\title{
PRÁTICAS DOCENTES NA CIBERCULTURA E O ESPERANÇAR DE PROFESSORAS NA PANDEMIA: \\ POSSIBILIDADES EDUCATIVAS PARA TORNAR O INÉDITO, VIÁVEL
}

TEACHING PRACTICES IN CYBERCULTURE AND THE HOPE OF TEACHERS IN PANDEMIA: EDUCATIONAL POSSIBILITIES TO MAKE THE UNPRECEDENTED, VIABLE

\section{PRÁCTICAS DIDÁCTICAS EN CIBERCULTURA Y LO ESPERANZAR DE LAS PROFESORAS EN PANDEMIA: \\ POSIBILIDADES EDUCATIVAS PARA HACER LO SIN PRECEDENTES, VIABLE}

Luciana Velloso ${ }^{1}$ Ana Clara São Thiago ${ }^{2}$ Karolyne Neves da Silva ${ }^{3}$

\section{RESUMO}

Neste artigo as autoras se propõem a refletir sobre suas experiências como professoras-pesquisadoras da cibercultura - cultura contemporânea mediada pelas tecnologias digitais em rede, em relação com a cidade e o ciberespaço, ao longo da pandemia do novo coronavírus e suas variantes/ COVID-19. Compreendendo a importância das práticas educativas no contexto da educação online, buscam criar 'sentidossignificações' outros, nas relações com os sujeitos praticantes de suas pesquisas, alunos de graduação do curso de Pedagogia da UERJ e alunos do Ensino Fundamental I de uma escola pública localizada no Complexo da Maré - RJ. Em termos metodológicos, apropriam-se dos princípios da ciberpesquisa-formação (Santos, 2019), bricolando-os aos estudos dos cotidianos (Certeau, 2013; Andrade; Caldas; Alves, 2019) e da multirreferencialidade (Ardoino, 1998; Macedo; Barbosa; Borba, 2012), a partir das contribuições de Freire (2020), no que tange ao 'inédito viável' e as rupturas com uma educação bancária, para dar espaço a uma educação libertadora. No entrelaçamento de suas

Submetido em: 31/05/2021 - Aceito em: 09/10/2021 - Publicado em: 13/10/2021

\footnotetext{
${ }^{1}$ Coordenadora do Grupo de Pesquisa Sociabilidades, Educação e Cibercultura SoCib/UERJ Professora do Programa de Pós Graduação em Educação em Comunicação, Culturas e Periferias Urbanas (PPGECC/ FEBFUERJ) e Professora Adjunta da Faculdade de Educação (UERJ). E-mail: lucianavss@gmail.com. Orcid: 00000002-6832-4189

2 Mestranda em Educação PPGECC/UERJ. Membro do Grupo de Pesquisa Sociabilidades, Educação e Cibercultura SoCib/UERJ. Professora dos anos iniciais na rede pública do Rio de Janeiro. E-mail: anasthiago41@gmail.com Orcid: 0000-0002-4508-715X.

3 Mestranda em Educação PPGECC/UERJ. Membro do Grupo de Pesquisa Sociabilidades, Educação e Cibercultura SoCib/UERJ. E-mail: karolynens.26@ gmail.com. Orcid: 0000-0002-7538-6046.
} 


\title{
Revista Docência e Cibercultura
}

pesquisas, movimentam-se em direção a um modo de 'fazerpensar' suas práticas educativas, de forma humanizada, concluindo que os trabalhos que dialogam com Freire demandam posicionamento de quem os escreve, e exigem, portanto, engajamento e escolha, posto que o ato pedagógico necessariamente é um ato político.

PALAVRAS-CHAVE: Cibercultura; Educação Online; Paulo Freire; Práticas Educativas;

\begin{abstract}
In this article, the authors propose to reflect on their experiences as professor-researchers of cyberculture contemporary culture mediated by digital networked technologies, in relation to the city and cyberspace, throughout the pandemic of the new coronavirus and its variants / COVID-19. Understanding the importance of educational practices in the context of online education, they seek to create other 'sense-meanings' in their relationships with the practitioners of their research, undergraduate students from the Pedagogy course at UERJ and students from Elementary School I of a public school located in Complexo da Maré - RJ. In methodological terms, they appropriate the principles of cyberresearch-training (Santos, 2019), bricolating them to everyday studies (Certeau, 2013; Andrade; Caldas; Alves, 2019) and multi-referentiality (Ardoino, 1998; Macedo; Barbosa; Borba, 2012), based on the contributions of Freire (2020), regarding the 'viable unprecedented' and the ruptures with a banking education, to make room for a liberating education. In the intertwining of their research, they move towards a way of 'making think' their educational practices, in a humanized way, concluding that the works that dialogue with Freire demand positioning from those who write them, and therefore require engagement and choice, since the pedagogical act is necessarily a political act.
\end{abstract}

KEYWORDS: Cyberculture; Online Education; Paulo Freire; Educational Practices

\section{RESUMEN}

En este artículo, los autores proponen reflexionar sobre sus experiencias como profesores-investigadores de cibercultura - cultura contemporánea mediada por tecnologías digitales en red, en relación con la ciudad y el ciberespacio, a lo largo de la pandemia del nuevo coronavirus y sus variantes / COVID-19. Comprendiendo la importancia de las prácticas educativas en el contexto de la educación en línea, buscan crear otros 'significados sensoriales' en sus relaciones con los practicantes de su investigación, estudiantes de pregrado del curso de Pedagogía de la UERJ y estudiantes de la Escuela Primaria I de un público. Escuela ubicada en Complexo da Maré - RJ. En términos metodológicos, se apropian de los principios de la ciberinvestigación-formación (Santos, 2019), bricolando a los estudios cotidianos (Certeau, 2013; Andrade; Caldas; Alves, 2019) y a la multireferencialidad (Ardoino, 1998; Macedo; Barbosa; Borba, 2012), a partir de los aportes de Freire (2020), sobre lo 'sin precedentes viable' y las rupturas con una educación bancaria, para dar cabida a una educación liberadora. En el entrelazamiento de su investigación, avanzan hacia una forma de 'hacer pensar' sus prácticas educativas, de manera humanizada, concluyendo que las obras que dialogan con Freire exigen posicionamiento de quienes las escriben, y por tanto requieren compromiso y elección, ya que el acto pedagógico es necesariamente un acto político.

PALABRAS CLAVE: Cibercultura; Educación en Línea; Paulo Freire; Prácticas Educativas;

\section{INTRODUÇÃO}

Já podaram seus momentos

Desviaram seu destino

Seu sorriso de menino

Tantas vezes se escondeu

Mas renova-se a esperança

Nova aurora a cada dia 
Revista Docência e Cibercultura

\author{
E há que se cuidar do broto \\ Pra que a vida nos dê flor e fruto \\ (Milton Nascimento ${ }^{4}$ - Coração de Estudante)
}

Não é possível predizer onde ou como se dará um acontecimento (GALEFFI, 2016). Por mais esperado que seja, não é previsível; "o acontecimento simplesmente acontece”. Como pesquisadoras, e diante da composição de nossas pesquisas, precisamos exercitar, diariamente, uma escuta e um olhar sensíveis, para aprendermos sobre e com os sentidos e significados dos acontecimentos cotidianos, dado que "compreendê-lo é participar dele acontecendo". Muitas vezes acontecimentos não esperados são aqueles que nos permitem ter uma visão mais ampla de quem somos e quais os nossos propósitos de atuação. Seriam os desvios do destino, como bem musicaliza Milton Nascimento.

Nesse sentido, em seus escritos, Freire (2020) traz uma perspectiva metodológica bem interessante, a do "inédito viável' ${ }^{5}$, que seriam soluções praticáveis, antes despercebidas. Esse termo poderia se tratar da própria vida, pelo fato de que o 'inédito' seria o acontecimento ainda não ocorrido e o 'viável' a possibilidade de sua ocorrência. Mas, como dois termos tão opostos se atraem? Qual o sentido que produzem juntos? Esta junção está relacionada à compreensão histórica como possibilidade, da qual decorre uma posição utópica que se opõe à visão fatalista da realidade. Desse modo, é preciso assumir um posicionamento diante do mundo, e implicarse, posto que a realidade não é, mas está sendo e, portanto, pode ser transformada.

Diante dessas considerações, estamos vivenciando um contexto de realidade diverso, inesperado. Ainda no início de 2020 a COVID-19, doença causada pelo novo coronavírus (SARS-CoV-2) se espalhou pelo nosso país e pelo mundo. Em março de 2020, a Organização Mundial da Saúde caracterizou a COVID-19 como uma pandemia. A partir desse momento, as formas de nos relacionarmos com as pessoas e as tecnologias digitais em rede, que há muito já não são mais as mesmas, são potencializadas diante do distanciamento físico que se fez necessário em meio à rápida contaminação da doença. Em maio de 2021, temos um quantitativo assustador de vidas levadas pelo vírus, chegando a 3.530 .582 de óbitos no mundo ${ }^{6}$, e 461.057

\footnotetext{
${ }^{4}$ Milton Nascimento é um cantor, compositor e multi-instrumentista brasileiro, reconhecido mundialmente como um dos mais influentes e talentosos músicos da Música Popular Brasileira. Disponível em: Wikipédia. Acesso em: 26 fev. 2021.

5 As ideias centrais que embasam nossas afirmativas encontram-se na nota explicativa de Ana Maria Araújo Freire, contida na obra Pedagogia da Esperança (2011, nota $n^{\circ} 1$, p.277-279), que são refletidas a partir do Pedagogia do Oprimido (2014), p. 149, 153 e 154.

6 Painel do Coronavírus da OMS (COVID-19). Visão geral. Atualizado em 30/05/2021. Disponível em: https://covid19.who.int/ Acesso em: 30 de maio de 2021.
} 
no Brasil ${ }^{7}$, situação ainda mais agravada no país devido à presença de um governo negacionista ${ }^{8}$ e o baixo e tardio investimento no plano nacional de vacinação 9 .

Para muitos autores que têm estudado esse momento pandêmico no mundo, esta não é apenas uma situação de crise, de exceção, e sim de agravamento do abismo socioeconômico existente, cuja situação de quarentena torna mais visível a injustiça, a discriminação, a exclusão social e o sofrimento (SANTOS, B., 2020). Morin (2020), por sua vez, apresenta reflexões históricas sobre as crises e pandemias que atingiram o mundo no último século, como, por exemplo, a gripe espanhola, da qual é um dos sobreviventes, e as consequências sociais pós-crises, ressaltando os desafios inevitáveis de um momento como esse. Dessa forma, torna-se fundamental pensarmos sobre o inédito viável (Freire, 2020) na perspectiva de nos tornarmos sujeitos de nossa formação, refletindo nossas experiências, amparadas em abordagens metodológicas que nos possibilitem esse engajamento.

Vivenciando a cultura contemporânea mediada pelas tecnologias digitais em rede, a cibercultura, e sua relação com a cidade e o ciberespaço (Santos, E., 2019), neste artigo a autoras procuram refletir sobre suas experiências como professoras-pesquisadoras da cibercultura - cultura contemporânea mediada pelas tecnologias digitais em rede, em relação com a cidade e o ciberespaço, ao longo da pandemia do novo coronavírus e suas variantes/ COVID-19, buscando (re)criar 'sentidossignificações '10 outros nas relações educativas com os sujeitos praticantes de suas pesquisas Os trabalhos e estudos desenvolvidos nesse momento do "inesperado" ambicionam relatar as problemáticas enfrentadas, bem como as soluções que emergem, de cada campo, "rotas de fuga", encontradas pelos sujeitos para pensar suas práticas, seus modos de ser e de agir diante do outro e do mundo, na busca de alternativas que não paralisem suas intenções, através dos caminhos da consciência de si (JOSSO, 2012).

Entendemos que não é fácil reverter, muitas vezes, as ações previamente planejadas, percursos que há tempos são trilhados em um único sentido, mas, emergem novas possibilidades na aurora de cada dia, e a escolha de cuidar do broto permite a existência da flor e do fruto. É preciso que nos movimentemos em prol de um revigoramento de nossas práticas docentes e discentes, neste

\footnotetext{
${ }^{7}$ Painel Coronavírus Brasil. Atualizado em 29/05/2021. Disponível em: https://covid.saude.gov.br/ Acesso em: 30 de maio de 2021.

8 Dois momentos em que Bolsonaro chamou covid-19 de 'gripezinha' - Disponível em: https://www.bbc.com/portuguese/brasil-55107536 Acesso em 20 de abr. 2021.

93 erros que levaram à falta de vacinas contra covid-19 no Brasil - por Natália Passarinho. Disponível em: https://www.bbc.com/portuguese/brasil-56160026 Acesso em 4 de mai. 2021.

${ }^{10}$ Optamos pela grafia deste e de outros termos juntos, em itálico e entre aspas, pelo fato de concordarmos com Andrade, Caldas e Alves (2019) que não é possível separar seus sentidos, dado que "as dicotomias necessárias à criação das ciências na Modernidade têm significado limites ao que precisamos criar na corrente de pesquisa a que pertencemos" (p. 19), ou seja, nas pesquisas com os cotidianos.
} 
cenário de medo, inconstância e imprevisibilidade, criando maneiras outras de educar a partir da empatia, da colaboração, da interatividade, do empoderamento, da autorização e da autonomia, indo além da simples esperança, que espera o acontecer. É preciso seguir pelas trilhas do "esperançar" como necessidade ontológica que, para lá da pura teimosia, "é imperativo existencial e histórico" (Freire, 2011, p. 14), essencial para a concretização da utopia, dos sonhos possíveis, numa mobilização que se faz em ato.

\section{ENTRELAÇAMENTOS TEÓRICO-METODOLÓGICOS}

Como professoras-pesquisadoras que somos, não podemos deixar de ser afetadas e afetarmos nossas pesquisas num cenário como o da pandemia, por meio da (re)existência do pesquisar em parceria e colaboração com nossos 'praticantespensantes "11. Nas pesquisas com os cotidianos (Andrade, Caldas e Alves, 2019), trabalhamos com a concepção de que os diversos ambientes educativos dos quais fazemos parte são 'espaçostempos' de pensamento e de criação de conhecimentos múltiplos e complexos. Desse modo, faz-se necessário modificar a forma como tratamos nossos 'objetos' de pesquisa, posto que lidamos com pessoas, que interagem, estão em constante movimento e, como seres pensantes, trazem os questionamentos de suas práticas. No cotidiano atual é importante refletir, ainda sob a perspectiva das relações mediadas pelo digital em rede, transformando nossas formas de interação com o outro, configurando outras possibilidades de ser e estar no mundo.

No contexto da cibercultura (Lévy, 1999; Lemos, 2020), e devido ao distanciamento físico necessário, o acesso a plataformas digitais diversas e aulas online no contexto educacional ganharam maior ênfase, tornando-se necessário pensar nos desafios e contribuições da educação online (Santos, E., 2019) para a prática de uma educação libertadora. Muitas instituições de ensino passaram a permitir o uso de dispositivos digitais para que as atividades escolares e acadêmicas pudessem ter continuidade em casa e, nesse cenário, alunos e professores sentem as diferenças das novas demandas que emergem, buscando por uma rápida adaptação de suas atividades acadêmicas e profissionais, trazendo à tona, com maior proporção, questões como a desigualdade do acesso às tecnologias e conectividade.

Neste momento, mais do que nunca, percebemos a importância de Freire (2020) tanto em nossas práticas pedagógicas, mostrando com clareza que "não há docência sem discência" (p.

\footnotetext{
11“Praticantespensantes”, praticantes culturais, ou somente praticantes, são os indivíduos que realizam uma prática com determinado grupo, envolvendo-se com certo sentimento de sentimento de identidade coletiva ao se relacionarem com os outros, por meio de um padrão de sociabilidade que os une (SANTOS, 2014; 2019).
} 
25), quanto em nossas práticas cotidianas, como docentes e discentes, no grande ir e vir que é a vida. Torna-se imprescindível (re)pensar as formas de educar, o que é educar e quais os sentimentos, emoções e engajamentos que envolvem esse processo. Krenak (2019) afirma que "fomos nos alienando desse organismo de que somos parte, a Terra, e passamos a pensar que ele é uma coisa e nós, outra" (p. 10). Nessa perspectiva, ao refletirmos sobre a educação no contexto da cibercultura, em diálogo com Paulo Freire, compreendemos que fazemos parte de um complexo organismo, no qual precisamos uns dos outros - professores, alunos, gestores, familiares, amigos e da grandiosa gaia - entrelaçados e tecidos em meio a uma rede de bordados, cósmica e natural, tornando-nos o que somos: seres que sentem, pensam e se movimentam!

Nesse sentido, os entrelaçamentos teórico-metodológicos que este texto apresenta, tecem sua estrutura com base em 'um rigor outro' (MACEDO, 2012), pautado na noção de bricolagem ${ }^{12}$, que emerge como experiência significativa que nos retira "as amarras da condução epistemológica disciplinar, dos padrões esperados, dos conceitos protegidos, dos conhecimentos pré-dirigidos", em que o pesquisador "se aventura na improvisação criativa diante das demandas e dos desafios propostos", tornando-se um transgressor responsável, que trai a ordem estabelecida na intenção de ultrapassar limites, fronteiras (MACEDO, 2012, p. 49$50)$.

Conscientes de que a arte de bricolar requer capacidade criativa, coragem, por parte dos professores-pesquisadores de se lançarem ao desafio de transformar os cenários formativos, implicando-se, de forma fecunda, no campo investigativo, bricolamos a pesquisa-formação na cibercultura (SANTOS, 2019) aos estudos dos cotidianos (Andrade; Caldas; Alves, 2019; Certeau, 2013) e aos princípios da multirreferencialidade (Ardoino, 1998; Macedo; Barbosa; Borba, 2012), para que fosse possível a elaboração de um novo conhecimento, em que saberes do cotidiano e saberes científicos se (entre)cruzam, conversam e se relacionam.

Concordamos com Ribeiro e Santos (2016) quando afirmam que "entretecer cibercultura e pesquisa-formação com inspiração epistemológica multirreferencial e com os cotidianos é uma opção política de condução a processos formativos emancipatórios" (p. 303), refletindo a respeito da pesquisa como uma "aventura pensada", que segundo Macedo (2020), envolve

\footnotetext{
${ }^{12}$ Ação de tecer junto, com coerência ética e política e, com um rigor outro possibilitando que o objeto de pesquisa seja abordado sob diversos ângulos, tornando possíveis avanços para questões e dimensões a ele inerentes (KINCHELOE; BERRY, 2007).
} 
projetos flexíveis em contato com a realidade, compostos de dispositivos heurísticos que procuram encontrar respostas por meio das descobertas, do que ainda é desconhecido.

Além disso, nossos modos de fazer pesquisa levam em conta o momento em que vivenciamos e a cultura do digital em rede, além conceber que o ciberespaço como um lugar de autoria, em que o praticante se forma enquanto pesquisa, e vice-versa, numa perspectiva ciber. A pesquisaformação na cibercultura concebe a práxis docente também na educação online (EOL) - um fenômeno da cibercultura, no qual os processos do 'aprenderensinar' possibilitam o compartilhamento de narrativas, sentidos, imagens, mediados pelas interfaces digitais que são percebidas como dispositivos de pesquisa-formação (SANTOS, E., 2019). Nesse percurso, as práticas formativas que possibilitam ao sujeito aprender enquanto ensina e ensinar enquanto aprende, emergem no ciberespaço, mediadas pelas tecnologias digitais em rede.

A mobilidade hoje já não está mais restrita apenas a espaços geograficamente localizados, mas também está muito fortemente relacionada ao ciberespaço, em que podemos estar em diferentes lugares ao mesmo tempo, sob a característica da ubiquidade (SANTAELLA, 2013). Podemos entender o ciberespaço como "o conjunto plural de espaços mediados por interfaces digitais" (SANTOS, E., 2019, p. 30), e nessa perspectiva, no momento em que se constroem nossas pesquisas, o ciberespaço é fortemente habitado por docentes e discentes na construção de relações e produção de múltiplos 'conhecimentossignificações' no contexto da pandemia e, para além dele.

No ciberespaço, desenvolvemos atos de currículo (MACEDO, 2020), buscando (re)criar maneiras outras de 'fazerpensar' educação, agora no online. Mas, para desenvolver atos de currículo num cenário pandêmico, é necessário construir uma relação baseada na dialogicidade que, nos moldes da educação online, estará intimamente ligada às suas características de interatividade, criação, colaboração, autoria e autonomização.

Atuar nessa direção não é tarefa das mais simples. Freire (2015) afirma que a profissão de professor(a) implica ousadia, na busca de formas de existir e resistir num cenário macro, desenvolvendo práticas outras, não apenas para continuar fazendo ciência no percurso de nossas pesquisas, mas refletindo os cotidianos a partir de suas vivências. Lembramos que "o mundo não é. O mundo está sendo" (FREIRE, 2020, p. 74) e enquanto o mundo acontece precisamos continuar sendo atores(as) e autores(as) de nossas itinerâncias (BARBIER, 2007), e como sujeitos históricos que somos, não constatamos para nos adaptarmos, mas para mudarmos (FREIRE, 2020) a realidade.

Diante disso, temos como objetivo apresentar 'práticasteorias' de duas professoraspesquisadoras com diferentes praticantes, mas que, em comum, se relacionam pela intenção de 
criar um movimento mais humano e holístico com o ser, compreendendo a importância das relações, dos fenômenos da cibercultura, dos atos de currículo e de uma educação baseada na dialogicidade. Assim, temos por intuito desconstruir a forma de 'fazerpensar' educação baseada em uma relação dicotômica aluno-professor, abrindo caminho para uma formação que comporta docentes e discentes, que, juntos, aprendem e ensinam, ensinam e aprendem, no 'fazerpensar' das práticas cotidianas que vão nos construindo e constituindo como seres humanos, pensantes, sujeitos e autores de nossas próprias histórias.

\section{UM MODO OUTRO DE 'FAZERPENSAR' EDUCAÇÃO UNIVERSITÁRIA A PARTIR DA FILOSOFIA DO YOGA PARA UMA EDUCAÇÃO LIBERTADORA NA CIBERCULTURA}

A palavra "Yoga" vem da raiz "Yuj", que significa unir, juntar, ligar (ELIADE, 1996). Partindo da premissa do Yoga clássico, o Yoga pode ser compreendido como uma filosofia, conforme é formulado nos Sutras de Patanjali (Patanjali, 2019), antigas escrituras que trazem o sistema filosófico do Yoga. O Yoga clássico formulado por Patanjali é o mais conhecido no ocidente (Eliade, 1996). Essa filosofia busca a conexão e equilíbrio entre três planos de existência nos seres humanos - corpo, mente e espírito -, partindo de uma proposta de educação espiritual que busca o autoconhecimento e o equilíbrio emocional.

Fundamentados nos princípios do Yoga, que pensa uma educação humana e integral, e que dialoga com a proposta de educação libertadora de Freire (2020), trazemos neste tópico um modo outro de 'fazerpensar' a educação universitária no contexto da cibercultura, percebendo nos relatos de alunos de graduação em Pedagogia da Universidade do Estado do Rio de Janeiro (UERJ) suas experiências com o Yoga em um dos módulos da disciplina "Controle e Gestão do Estresse", dedicado ao tema "Yoga e autoconhecimento", e as possíveis relações que essa filosofia pode ter com suas práticas de 'aprendizagemensino' 'dentrofora' do ciberespaço.

Numa educação formal que molda corpos dóceis (Foucault, 1999), é preciso pensar em uma educação libertadora, humana e holística não dissociadas da preparação do aluno em sua formação para o exercício pleno de sua cidadania. A educação, com todo seu potencial transformador, leva-nos a caminhos jamais imaginados, mas que, em meio às demandas de um contexto capitalista, no qual precisamos nos adequar ao mercado de trabalho, bem como desfrutar de alegrias "vendidas", podemos esquecer de todo esse poder que possuímos dentro de nós.

Em "Vigiar e Punir", Foucault (2014) nos fala sobre instituições que contribuiriam para a sistematização da vigilância e da padronização de comportamentos dos indivíduos, como 
maneira de praticar a punição, agora por meio da disciplina, e não do castigo físico. Entre essas instituições, a escola se apresenta como espaço onde a disciplina e o tempo são trabalhados para que o indivíduo seja produtivo e alcance níveis predeterminados que mediriam sua aprendizagem. Desse modo, pensando na escola atual como instituição para formar cidadãos e cidadãs que possam exercer sua plena cidadania, contrapomo-nos a essa concepção de escolainstituição, que busca medir os avanços e processos de cada indivíduo rumo a categorias/níveis/séries estabelecidos por outros, diferentes dos que são "moldados", ou seja, aqueles que vivem os processos avaliativos nas instituições de ensino, por entendermos que essa prática pode resultar em experiências que não permitam ao aluno explorar seus diferentes potenciais, direcionando-o para caminhos que, em muito, podem oprimir suas singularidades.

Nessa direção, podemos vislumbrar, no Yoga, uma educação que permitirá que o indivíduo seja livre, vivendo plenamente sua capacidade de ser e estar no mundo, de forma autêntica, diferentemente da escola e da universidade que, como instituições normalizadoras, por vezes reprodutivas de uma educação bancária (Freire, 2020) e que produz corpos "dóceis", corpos fáceis de serem "moldados", em meio às necessidades impostas pela cultura capitalista, acabam provocando o processo contrário sob seus alunos, ou seja: potencialidades se esvaem em face das necessidades de adaptação ao mercado de trabalho e às demandas econômicas. A escola passa cada vez mais a pensar em uma educação corporativa, que busca formar líderes e mão de obra para o mercado, mas não líderes de si mesmos.

Freire (2020) argumenta que a dialogicidade se faz extremamente necessária nos processos de formação que ocorrem em diferentes ambiências, pois abre espaços para que novos saberes sejam construídos em parceria, por docentes e discentes. Sob esta ótica nos perguntamos: os espaços formais de educação têm permitido que mais alunas e alunos sejam vistos através de suas potencialidades, encontrando possibilidades de desenvolvê-las, compartilhá-las e delas fazerem uso para construir novas formas de 'fazerpensar' coletivamente?

Refletindo sobre esse 'fazerpensar' coletivo, ampliamos esse repertório de performances criativas e relacionais, uma vez que a cibercultura compreende um conjunto de práticas e modos de pensamento que se desenvolvem junto com o ciberespaço, através de uma conexão generalizada em rede, possuindo como características, em sua fase atual da web 2.0, as novas tecnologias de conexão móvel ( $W i-F i$ e redes $2 \mathrm{G}, 3 \mathrm{G}, 4 \mathrm{G}$ ), a possibilidade de interatividade, criações autorais e colaborativas em rede e a mobilidade ubíqua em uma conexão entre cidadeciberespaço (SANTOS E., 2019). Assim, as ações praticadas 'dentrofora' do ciberespaço interagem e alimentam a configuração dessa cultura ciber. Para Lemos (2020), a cibercultura "vai se caracterizar pela formação de uma sociedade estruturada através de uma conectividade telemática generalizada, ampliando o potencial comunicativo, proporcionando a troca de informações sob as mais diversas formas, fomentando agregações sociais” (p. 88). 
Com isso, essa "conectividade telemática generalizada" possibilita que agora possamos acessar e compartilhar informações em vários lugares ao mesmo tempo, não apenas como receptores, mas também como autores e emissores de informações e conteúdos variados. Sobre suas influências e contribuições nas/para as práticas educativas, concordamos com Santos, E. (2019), quando diz que o cenário atual da cibercultura e da mobilidade ubíqua "é favorável a educação democrática" (p.33) e chama a atenção para a inclusão do professor nesse contexto cibercultural, pois a autoria, conectividade e interatividade, características da educação online, proporcionam uma melhor performance do professor em colaboração com o aluno, a partir de práticas pedagógicas que se baseiam em "autonomia, diversidade, dialógica e democracia" (p. 33).

Assim, a inclusão dos docentes é necessária para que não esteja alheio aos fenômenos ciberculturais, pois não bastarão os acessos ilimitados aos recursos tecnológicos se faltarem práticas pedagógicas para trabalhar junto a esses recursos. É importante ressaltar isto, para que na educação online não se repitam as armadilhas da educação bancária, utilizando as interfaces digitais e as conexões em rede apenas para continuar 'depositando' conhecimento nos alunos, em uma relação unilateral, fazendo comunicados ao invés de comunicar-se (FREIRE, 2020). É preciso inventar e reinventar práticas educativas, em atos de currículo, para colocar em prática as características e objetivos da educação online.

Em 2020, por meio de uma pesquisa no Google por "Yoga online na pandemia", encontramos diferentes matérias em jornais e websites sobre, por exemplo: a adaptação do Yoga online durante a pandemia ${ }^{13}$; como o Yoga pode ajudar a aliviar o estresse no contexto pandêmico ${ }^{14}$; o Yoga online como alternativa para cuidar da saúde na pandemia ${ }^{15}$; entre outros. Pensar, então, na proposta dessas práticas, de forma online, como parte dos processos de formação de 'docentesdiscentes' na universidade, exige também pensar na questão do acesso à Internet, que lhes possibilite assistir, interagir, produzir e realizar as práticas.

Organização das Nações Unidas (ONU, 2011), declarou o acesso à Internet um direito humano ${ }^{16}$. Logo, o acesso democrático às práticas de Yoga online, pressupõe o acesso democrático a uma Internet banda larga de qualidade, favorecendo, por exemplo, a realização

13 Ver mais em "Ioga on-line se adapta para novo público durante a pandemia". Disponível em: https://glo.bo/2H8fqBS. Acesso em: 16 novembro 2020.

${ }^{14}$ Ver mais em "Yoga pode ajudar a aliviar estresse na pandemia". Disponível em: https://bit.ly/2ICE7Y6>. Acesso em: 16 novembro 2020.

${ }^{15}$ Ver mais em "Yoga online é alternativa para cuidar da saúde e bem-estar durante a pandemia". Disponível em: https://bit.ly/2H7QMRR. Acesso em: 16 novembro 2020.

16 Ver mais em: "Relatório da ONU declara internet como um direito humano". Disponível em: https://bit.ly/3fNJsaS. Acesso em: 29 novembro 2020. 
de videochamadas, que seria a principal forma de realização das práticas de Yoga online e ao vivo. Diante do exposto, não podemos nos fazer omissos àquelas e aqueles que tanto a prática do Yoga quanto uma conexão de qualidade - ou até mesmo qualquer conexão - se fazem distantes, nos provocando a identificação evidente e urgente da necessidade de políticas públicas que possibilitem o acesso democrático de conexão à Internet.

Alinhada a proposta de uma Educação Online, que não deve ser entendida como uma evolução do modelo de Educação a Distância (SANTOS E., 2019), refletimos sobre a Yoga online como parte de uma conjuntura social, no contexto da cibercultura, que ressignifica e amplia as formas de nos relacionarmos em sociedade, e de realizarmos essa prática milenar, seja como atividade relacionada simplesmente ao bem-estar físico, seja como prática educativa que propõe uma educação mais humana e integral, que busca o equilíbrio entre corpo, mente e espírito, trabalhando nossas emoções e sentimentos. Como, então, pusemos em prática essa proposta, e que 'sentidossignificações' essa experiência proporcionou aos seus praticantes?

Após a aula de Yoga e Autoconhecimento com a turma de graduação em Pedagogia da UERJ, a praticante $\mathrm{Padma}^{17}$ indicou que começou a prática do Yoga após a aula síncrona da disciplina, realizada pela plataforma Zoom, e que em relação ao estresse ao qual estava submetida naquele momento "foi fundamental fazer [...], pois com essa questão de ir trabalhar todos os dias e dar conta das disciplinas online está exigindo muito oxigênio o meu cérebro [...]" (PADMA, aluna de Pedagogia da UERJ, 2020). A fala de Padma instiga-nos a investigar e refletir sobre os esgotamentos que podem ocorrer em meio a essa modalidade de ensino remoto, se o cenário e os contextos vivenciados por docentes $e$ discentes não contribuírem para que a experiência seja a melhor possível.

Nessa perspectiva, e considerando o momento da pandemia, a praticante Shanti toma a seguinte decisão em relação aos usos no digital em rede: "tive como iniciativa, para contornar esse momento, a ideia de desativar todas as minhas redes sociais e reservar um tempo pra fazer algo que me fizesse bem". Sobre as práticas de Yoga e suas contribuições, ela conclui: "percebi que manter uma rotina com coisas que me acalmam, longe de redes sociais e praticando Yoga e exercícios de respiração é possível entender que os momentos ruins passam e que logo as coisas irão melhorar" (SHANTI, aluna de Pedagogia da UERJ, 2021). Diante da decisão de Shanti, de se afastar das redes como uma ação que poderia lhe fazer bem, é importante ressaltarmos que os cenários, contextos e vivências não favoráveis, podem tornar mais difíceis as experiências 'dentrofora' do online. No que tange às contribuições do Yoga, Shanti encontra esperança na possibilidade de superação por meio dessa prática.

${ }^{17}$ Com o objetivo de preservar a identidade dos praticantes, foram escolhidos nomes fictícios relacionados à cultura do Yoga para representá-los. 
O caso de Shanti, e de muitos outros docentes e discentes que estão vivendo a pandemia, pode ter muita relação com a infodemia, "um excesso de informações, algumas precisas e outras não, que tornam difícil encontrar fontes idôneas e orientações confiáveis quando se precisa" (OPAS, 2020, p.1).

Em meio a avalanche de informações, que mexe com toda a conjuntura social e econômica neste momento, esgotamentos físicos e emocionais surgem, não devendo ser desconsiderados, quando pensamos nas potencialidades de 'aprenderensinar' no contexto da educação online e de suas interfaces digitais, de forma que possam contribuir para evitar uma possível desmotivação e/ou exaustão mental como a trazida no relato de Padma - que não está apenas relacionada às atividades no online, mas a todas as outras circunstâncias e atividades cotidianas realizadas 'dentrofora' do ambiente virtual, e que, portanto, corroboram para desdobramentos que podem impossibilitar o bom aproveitamento das experiências nesse contexto.

O 'aprenderensinar' precisa se alinhar às contribuições de Freire (2020) sobre uma prática de construção de saberes pautada na colaboratividade e na interatividade, já que "ensinar inexiste sem aprender e vice-versa" (FREIRE, 2020, p. 25). Essa troca entre professores e educandos se faz extremamente importante. As telas dos celulares e computadores não devem continuar mantendo uma distância relacional entre esses dois grupos que muito têm a ensinar e aprender juntos; pelo contrário, devem ser úteis para impulsionar práticas que busquem desconstruir este paradigma.

O Yoga e suas práticas podem aproveitar as potencialidades do online, utilizando diferentes plataformas para, por meio do digital em rede, se tornarem mais acessíveis e incorporadas às práticas educacionais 'dentrofora' da universidade. Importante ressaltar que não é o ambiente online por si só que irá definir o que é educação online (SANTOS E., 2019), mas sim os movimentos pedagógicos, a interação entre os sujeitos envolvidos, as práticas colaborativas, comunicacionais, de autoria e interação que fazem parte dessa modalidade de ensino.

Conversamos com nossos referenciais para nos autorizarmos a dizer que esse movimento para dentro que faz o Yoga e que, consequentemente, também vai para fora a partir de nossas práticas cotidianas coletivas, pode trazer contribuições outras ao ser, que não se resumem a bons aproveitamentos acadêmicos no que tange a notas, processos avaliativos, produção de papers; mas, para além disso, torna a aprendizagem sensível e acessível, permitindo que os potenciais criativos e transformadores desabrochem, mesmo nos lugares e circunstâncias mais improváveis.

Pensando na função do Yoga nos diferentes processos formativos 'dentrofora' do online, e 
olhando não apenas para os discentes, mas também para os docentes como seres únicos, sua filosofia é trazida como proposta para pensar na integração entre corpo e mente, que desenvolve, valoriza e potencializa suas singularidades e que, independentemente do espaço em que ocupe, possa incentivar uma forma de educar, na qual o "sentimento do mundo" (Andrade, Caldas e Alves, 2019) possa ser vivido nesses processos.

Quando falamos de corpos dóceis em Foucault (2014), pensamos numa forma de 'aprenderensinar' voltada para a normalização dos corpos e dos processos tratados como formativos. Desde crianças, aprendemos a nos comportar de uma maneira na escola, atingir as notas através de avaliações em disciplinas e sermos cobrados a partir da demonstração de uma insuficiência dos resultados dessas avaliações, bem como de uma incapacidade de cumpri-las. Essa forma de ensinar, por vezes, está muito relacionada a uma educação bancária que busca depositar conhecimento no aluno. Assim, estudantes vão passando apenas a receber informações, que não necessariamente se transformam em saberes críticos, uma vez que a falta de dialética não permite a troca entre docentes e discentes para promover a construção de 'conhecimentossignificações' outros.

Partindo desse princípio, pensar na filosofia do Yoga como parte de uma educação libertadora é importante para compreendermos o que seria o processo de re(educação) do corpo e da mente na educação universitária. Uma vez que nossa educação costuma se pautar em cumprir metas, atender às demandas do mercado de trabalho e às necessidades de produção em uma sociedade capitalista e globalizada, é cada vez mais comum nos encontrarmos com uma educação corporativa, que pode reproduzir formas de "transmitir" conhecimento, característica da educação bancária, que tem o professor como protagonista do processo de' aprenderensinar' Nessa perspectiva, para além do "transmitir", é necessário a adoção de uma metodologia que possibilite não apenas transmitir, mas dialogar e permitir aqueles e aquelas que 'aprendemensinam', se coloquem no mundo como sujeitos histórico-sociais.

Com efeito, o Yoga desperta a consciência de si, mas, também, a consciência de se manter atento ao outro (Flak; Coulon, 2007), sendo possível trabalhar participações mais coletivas e sensíveis. Partindo dessa proposta, é possível pensar em uma educação do eu que não exclui sua convivência com o outro, e a importância dessa convivência para se construir uma sociedade saudável. Essa filosofia de vida se entrelaça com os pressupostos da educação online, que explora as potencialidades de uma educação relacional e a construção de saberes pensados e construídos em coletividade.

Concordando com o pensamento de Macedo (2020, p. 22), que:

o ato de currículo como uma concepção curricular epistemológica valorada cria a 
antítese da visão de currículo como uma condenação sociopedagógica, como um artefato neutro que produz tão somente prescrição, restrição e trilhos" (p.22) provocando uma disposição para uma implicação irrestrita nas coisas do currículo, aqui perspectivado como uma invenção social e cultural, com possibilidades de se transformar em uma multicriação socioeducacional numa experiência autonomista compartilhada".

sendo, portanto, ações que desconstroem o modo de trabalhar currículo de forma inflexível, seguindo um "menu" fixo fora de negociações de alterações e ressignificações, a filosofia do Yoga pode ser inserida e praticada nas práticas educacionais na universidade e na educação online. Daí, a importância da (re)significação das nos processos de repensar educação do corpo e mente na universidade.

A experiência vivenciada no módulo Yoga Autoconhecimento, nos mostrou a possibilidade de trazer a filosofia do Yoga para as práticas educativas, em atos de currículo, no contexto da cibercultura. Nesse contexto, foi elaborado um texto de apoio para os alunos e uma videoaula, mostrando uma prática curta de Yoga, com técnicas simples que poderiam ser inseridas nas rotinas dos graduandos, e uma aula síncrona para falarmos sobre as experiências com o módulo, na qual muitos alunos relataram suas impressões sobre o Yoga no cenário universitário. Shiva, um dos alunos praticantes da pesquisa, trouxe alguns de seus sentimentos em relação a universidade e sua vida e o reconhecimento da prática da meditação, umas das técnicas do Yoga, como algo que proporciona "equilíbrio emocional".

Ao entender essa prática como parte das contribuições do Yoga para uma nova forma de 'fazerpensar' a educação universitária, a praticante Surya também pensa o Yoga em sala de aula: "Compreendendo a importância do Yoga para todos, imagino como seria gratificante se estivéssemos em sala de aula o praticando, o alívio que contribuiria aos corpos e mentes daqueles/as que chegam em sala na correria pós um dia cansativo de expediente no trabalho" (SURYA, aluna de Pedagogia da UERJ, 2020).

Essas práticas em sala de aula, como proposto por Surya, em muito poderiam contribuir também para aliviar o tráfego de pensamentos e trazer a concentração para iniciar mais uma parte do dia, que nesse caso seriam os estudos na faculdade, após todo um dia de trabalho. Devemos, inclusive, ressaltar que os cenários em que vivem os graduandos podem ser/são diversos, mas mesmo em meio a essas pluralidades, podemos afirmar que, em algum momento, todos precisarão atender a demandas cognitivas em seus processos formativos na educação universitária, ainda que alguns sintam com mais intensidade que outros.

Os relatos de nossos praticantes graduandos, em ressaltam e confirmam a contribuição do Yoga em seus processos de 'aprendizagemensino'. E no momento da pandemia do novo coronavírus, 
eles mostram a importância dessa prática em suas rotinas, ao precisarem lidar com suas demandas pessoais, profissionais e acadêmicas.

Na construção de possibilidades para as contribuições do Yoga na educação universitária na contemporaneidade, é preciso e inevitável nos enxergarmos no contexto da cibercultura, pensando as formas de nos relacionarmos por meio do digital em rede, nas práticas de Yoga como forma de democratizar o acesso a sua filosofia; e em atos de currículo, trabalhar seus pressupostos nas relações cotidianas 'dentrofora' das instituições formais de ensino, caminhando para uma educação libertadora.

\section{OS USOS DAS TECNOLOGIAS DIGITAIS EM REDE E RELAÇÕES 'DOCENTESDISCENTES' NO COMPLEXO DA MARÉ EM TEMPOS DE PANDEMIA}

Ao longo da vida, enfrentamos diferentes situações que acreditamos ser intransponíveis, como barreiras que nos impedem de seguir adiante. São as situações-limite (Freire, 2020), em que nos sentimos imobilizados a agir; e, assim, ultrapassá-las dependerá de nossas escolhas e o quão conscientes estaremos a respeito delas. Se acreditarmos que são determinantes históricos, poderemos paralisar diante da ação, o que só poderá ser rompido por meio de uma práxis libertadora, por meio da ação-reflexão, em que deixamos de 'ser menos' para 'Ser mais'.

Diante dos imperativos da pandemia na qual estamos mundialmente inseridos, temos possibilidades de compreender e ultrapassar essas barreiras através de 'práticasteorias' que aqui apresentamos, tendo como principal interlocutor Paulo Freire. Em diversas esferas de ação em sociedade, podemos refletir sobre suas palavras, de modo a reinventá-lo, contextualizando suas proposições na contemporaneidade.

Em tempos de pandemia da COVID-19, a educação é um dos campos mais afetados pela necessidade do distanciamento físico. Segundo o acompanhamento da UNESCO, um pouco mais de um ano após o início da pandemia COVID-19 (março/2020), quase metade dos estudantes do mundo ainda é afetada pelo fechamento parcial ou total das escolas, o que representa mais de 1,5 bilhão de pessoas; "e mais de 100 milhões de crianças cairão abaixo do nível mínimo de proficiência em leitura como resultado dessa crise de saúde" (UNESCO ${ }^{18}$, 2020). Além disso, pontuam-se questões como a nutrição e proteção de crianças que dependem da instituição escolar para ter os seus direitos básicos à vida assegurados.

Diante da necessidade de não paralisar as aulas e reduzir as desigualdades, governos, escolas, professores, alunos e sociedade de todos os países buscam soluções para manter as relações de 'aprendizagemensino', e as práticas a distância emergem com maior intensidade para dar conta

\footnotetext{
${ }^{18}$ Disponível em: https://pt.unesco.org/covid19/ Acesso em 06 mai 2021.
} 
do cenário vigente, não obstante as questões da baixa infraestrutura de conexão e acesso às tecnologias por grande parte da população mundial ${ }^{19}$.

Esse percurso de luta é uma necessidade ontológica do ser humano, que ao longo da História se depara com situações que exigem que nos coloquemos à frente das limitações que se impõem, mediante a esperança em ato, no embate que desarvora, que mobiliza, visto que todos temos por vocação a humanização que é o Ser mais. Neste mesmo sentido, Morin (2020) afirma que a "esperança está na luta pelo despertar das mentes e pela busca de outra Via" (p. 53), via essa que comporta "(a) uma política nacional; (b) uma política civilizacional; (c) uma política de humanidade; (d) uma política da Terra; (e) um humanismo regenerado" (p.56), que envolve o abafar do individualismo e o despertar real da coletividade.

Então, como perpetuar as relações do 'aprenderensinar' mobilizados pela esperança? São diversos os trabalhos educativos relatados e demonstrados nesse momento, por meio de interações no ciberespaço, possibilitadas pelo digital em rede e plataformas digitais, confirmadas no esforço dos docentes de que é preciso perpetuar as relações frente às adversidades. Dessa forma, traremos também nestes escritos as 'práticasteorias' de uma professora dos anos iniciais, especificamente no $4^{\circ}$ ano do Ensino Fundamental, inserida na periferia do Complexo da Maré $(\mathrm{RJ})^{20}$, refletindo e conversando com suas vivências e implicações dos atravessamentos atuais em sua atuação.

Nesse sentido, nosso percurso investigativo reconhece a relevância da pesquisa-formação na cibercultura como articulação epistemológica e metodológica que potencializa o surgimento de autorias-cidadãs (SANTOS, E. 2019) na qual o(a) professor(a)-pesquisador(a) valoriza os cotidianos como 'espaçotempos' de produções. Dessa forma, acontecimentos são compreendidos em suas singularidades, tornando-se imprescindível tecer relações 'afetoeducativas' nas ambiências online em conversas com nossos 'praticantespensantes', por meio de dispositivos formacionais diversos, em práticas pedagógicas que se inspirem na multirreferencialidade.

"Professora, amanhã vai voltar a escola?" - uma das mensagens mais recorrentes recebidas por docentes em 2020. As respostas, marcadas pela incerteza do amanhã, eram também escritas sob a dor da saudade e da tristeza pelo afastamento físico. Passamos a sentir falta de algo que vai muito além de nossas rotinas, - do cheiro da comida da escola, das gargalhadas de nossos pequenos, dos abraços de cada dia, das cartas de afeto após um dia cansativo: sentimos falta da

\footnotetext{
19 Segundo estudo da ONU (2019), 3,6 bilhões de pessoas ainda estão excluídas da comunicação online Disponível em: https://news.un.org/pt/story/2019/11/1693711. Acesso em 28 de mai 2021.

${ }^{20} \mathrm{O}$ nome da escola, dos alunos e dos responsáveis relatados nestes escritos serão fictícios, preservados por motivos éticos de pesquisa.
} 
'escolavida' muito mais do que a escola-conteúdo. Assim, sabendo da necessidade de continuar nossos 'fazeressaberes', buscamos possibilidades outras de viabilizar esses contatos.

A turma aqui referida possui um quantitativo de 33 alunos, os quais possuem diferentes situações socioeconômicas e de localização na Maré. Grande parte habita a Baixa do Sapateiro, uma das 16 favelas que fazem parte desse complexo de favelas que é um dos maiores e mais populosos $^{21}$ da cidade do Rio de Janeiro, enfrentando situações de descaso governamental e de violência, que infringem seus direitos como cidadãos. A cidade, que em sua elaboração, se fortalece na opressão e exclusão dos sujeitos periféricos, perpetua o poder temporal, através da marginalização necessária ao controle central. Tratando do termo periféricos, Pombo e Dias (2020, p. 9) afirmam que este

remete a uma posição em função do que é considerado centro, sendo um território ou uma situação, havendo atribuição de maior valor ao que é central e atribuição de certo estigma ao que é periférico e marginal. [...] A condição de periférico $[. .$.$] se nutre entre confluências de posições de cor, gênero e classe.$

Sabendo das dificuldades que enfrentam em seus cotidianos, inicialmente, procuramos interagir com esses alunos mediante o envio de atividades a cada semana, tendo o grupo de WhatsApp com responsáveis o meio de maior possibilidade comunicativa, principalmente pela faixa etária dos alunos e pelo quantitativo de aparelhos móveis por residência. Mais adiante, percebendo que o retorno à escola, presencialmente, levaria mais tempo do que o esperado, sentimos a necessidade de mapear os alunos com relação ao acesso, colocando à mostra os quantitativos abaixo (Gráfico 1)

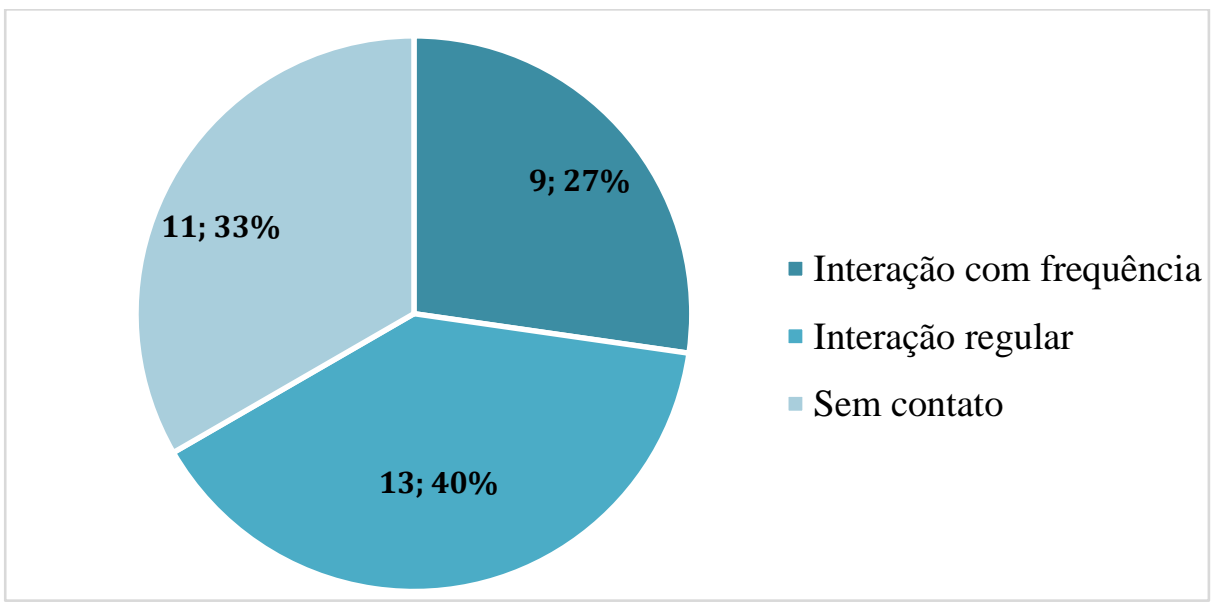

Gráfico 1 - Panorama de acesso e conectividade - turma 1401 Fonte: THIAGO, 2021.

\footnotetext{
${ }^{21}$ Segundo o Censo Populacional da Maré, realizado em 2013 pela Associação Rede de desenvolvimento da Maré. Disponível em: https://www.redesdamare.org.br/br/info/12/censo-mare Acesso em: 02 de nov. 2020
} 
Os números discriminados, acima, evidenciam a problemática da acessibilidade que aflora a cada dia em concomitância às necessidades básicas de vida, como a fome. Em conversa com os responsáveis da turma, através de ligações telefônicas e mensagens pelo aplicativo WhatsApp, para compreender os motivos do acesso irregular ou até de sua impossibilidade, obtivemos devolutivas muito impactantes, as quais destacamos algumas narrativas como a de Amanda: “professora, não 'to' conseguindo acessar as atividades que a senhora passa para o Arthur., não tenho mais Internet. 'tamos' esperando a chegada da cesta básica, estou desempregada e não 'tá' fácil sabe..."; e a de Selma: "Tia, não 'to' podendo comprar Internet não. O dinheiro que chega vai direto pro nosso prato”. (AMANDA; SELMA, responsáveis dos alunos Arthur e Elena (respectivamente), 2020)

Nessas falas relembramos Carolina Maria de Jesus ${ }^{22}$, que em seu diário relata os cotidianos da Favela do Canindé em São Paulo, que muito além de histórias pessoais, possuem marcas do racismo, da discriminação, da desigualdade social, de questões políticas e identitárias. Carolina nos faz sentir as suas dores, ver a cor da vida, amarela, impactada pela fome, que atravessa suas palavras e chega até nós, leitores. Nesse viés, enfatizamos que os cotidianos precisam ser refletidos em profundidade, em todos os seus sentidos, de modo que é preciso mergulhar inteiramente nos seus cheiros, gostos, olhares, deixando se tocar pelo caminho (ANDRADE, CALDAS, ALVES, 2019). A periferia nos traz sentimentos de uma localidade abandonada pelo poder público, que precisa ser compreendida para além de seus estereótipos, para a transformação desta realidade.

Para os alunos que tinham pouco ou nenhum acesso, foram disponibilizadas apostilas físicas nas escolas para que se perpetuasse uma mínima relação, e, na procura de encontrar viabilidades de trabalho com os educandos que tinham acesso regular e constante, verificamos outras informações importantes para tornar esse contato viável. Uma questão essencial é a de que $100 \%$ desses alunos que obtinham acesso, conseguiam estabelecê-lo através de dispositivos móveis (smartphones), que em $80 \%$ dos casos pertenciam aos seus responsáveis, situação essa que precisaria ser pensada no planejamento das atividades pedagógicas. Outra questão a ser analisada é a de que o aplicativo em que houve maior interação é o WhatsApp, ${ }^{23}$ apontado como

\footnotetext{
${ }^{22}$ Carolina Maria de Jesus, escritora, poetisa e compositora brasileira, mais conhecida pela obra "O Quarto de Despejo - diário de uma favelada (1960)".

${ }^{23}$ Multiplataforma de mensagens instantâneas e chamadas de voz para smartphones. Além de mensagens de texto, os usuários podem enviar imagens, vídeos e documentos em PDF, além de fazer ligações grátis por meio de uma conexão com a internet. Disponível em: https://pt.wikipedia.org/wiki/WhatsApp. Acesso em 26 de mai. 2021.
} 
emergente da $3^{\circ}$ fase (atual) da educação online ${ }^{24}$, e que vem ganhando ainda maior uso nesse último ano de $2020^{25}$, no qual tivemos de fortalecer nossos vínculos por meio do digital.

Através desse breve panorama, foi possível pensar estratégias de trabalho pedagógico e de interatividade, concebendo os princípios da educação online (SANTOS, E. 2019), na percepção de que era preciso ir além do currículo imposto. Era preciso ir adiante aos modos de pensar hegemônicos (Andrade, Caldas, Alves, 2019) nos conectando em horários diversos durante o dia para viabilizar a interatividade. As respostas às atividades propostas eram validadas por áudios, vídeos, imagens, conversas, em palavras, que muito além de contemplarem o conteúdo trabalhado, evidenciaram a necessidade de expressar sentimentos e emoções pelo momento vivido.

Entre os sentimentos que circundaram esse momento, emerge a insegurança de responsáveis com relação aos conteúdos pedagógicos trabalhados, como relata Jacira: "eu não sei explicar o dever a ela (aluna) e não tenho tempo pra isso, o que me deixa triste”. (JACIRA, responsável da aluna Mariana, 2020). Danuza, por sua vez, traz os desafios em lidar com os processos educativos de três crianças de diferentes idades em uma mesma casa, tendo somente um aparelho móvel para realizar tal processo, buscando táticas (CERTEAU, 2013) para subverter esses impositivos: "Professora, eu coloco ele pra copiar do quadro enquanto faço o almoço, ensino à irmã menor, deixo o outro pequeno copiando o alfabeto e a noite te mando as dúvidas dele, porque pra mim fica muito difícil”, (DANUZA, responsável do aluno José, 2020), situação demonstrada na imagem a seguir (Figura 1)

\footnotetext{
${ }^{24}$ A Educação Online é compreendida como fenômeno da cibercultura (SANTOS, E., 2005, 2019), visto que se atualiza a todo momento, concebida "em um conjunto de ações de ensino-aprendizagem ou atos de currículo mediados por interfaces digitais que potencializam práticas comunicacionais interativas e hipertextuais" (Ibid, 2019, p. 162)

${ }^{25}$ WhatsApp é o aplicativo mais usado pelos brasileiros na quarentena - por Daniel Junqueira. Disponível em: https://olhardigital.com.br/2020/07/31/coronavirus/. Acesso em 29 de abr. de 2021.
} 


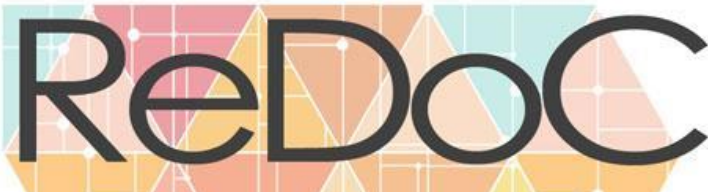

\section{Revista Docência e Cibercultura}

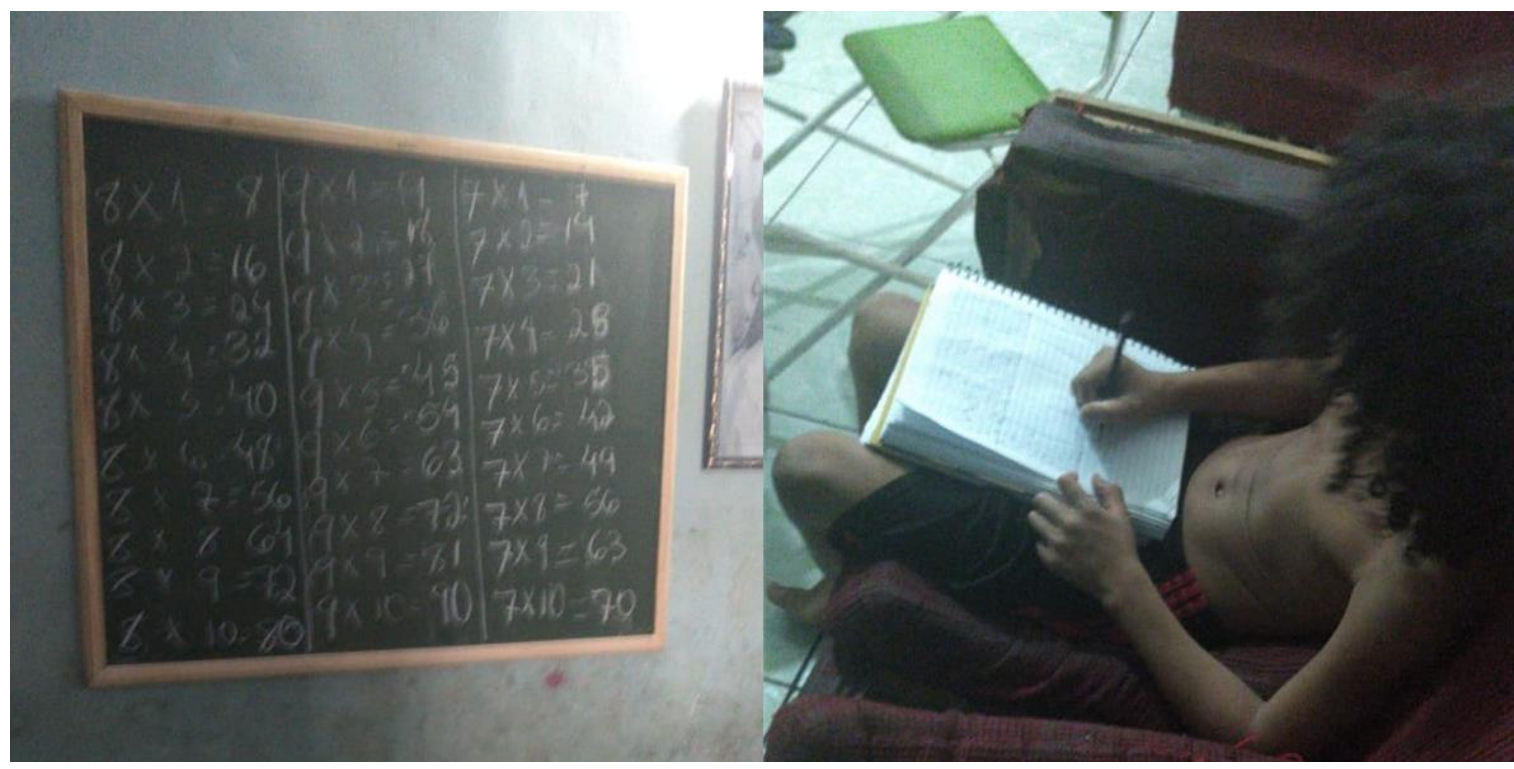

Figura 1: Desafios de 'ensinoaprendizagem' na pandemia Fonte: Acervo da autora, 2021

Diante da saudade, muitos alunos ultrapassaram as barreiras do distanciamento para contar suas experiências, compartilhar os seus dias. Em uma dessas trocas, por meio de áudio no WhatsApp, Anna chegou a desabafar sobre a falta que sente da escola nesse momento: "Eu tô com muita saudade da escola, sério... Eu nunca pensei que eu fosse sentir tanta saudade da escola, sabe por quê? Porque, tipo, no começo assim, eu não gostava muito de acordar cedo e tal, de ir para a escola e tal, de estudar né, porque quase ninguém gosta de estudar...(risos) Mas, mano, ficar o ano inteiro, o ano i-n-t-e-i-r-o sem ir para a escola, ai... Eu to com saudade de todo mundo, to com saudade dos meus amigos, to com saudade da senhora, sério... TÔ COM MUITA SAUDADE!'” (ANNA, aluna da turma do $4^{\circ}$ ano, 2021)

O relato de Anna desponta singularidades pouco percebidas anteriormente na escola, evidenciada nas questões atuais, da necessidade da amorosidade e afetividade, tanto para docentes, quanto para os discentes e seus familiares nas relações cotidianas. O que mais é levado em conta nesse contexto é a falta que faz essa relação, as vivências da escola, dos acontecimentos, dos abraços, das palavras ditas e não ditas.

A pandemia tem trazido consigo esse sentimento de espera do inesperado, do amanhã, desse 'inédito viável'. Mas esse 'esperar' não é algo que ocorre na inércia, e sim no 'esperançar' que destaca Paulo Freire, do agir, do ir adiante, que envolve essa comunicação entrecortada pelas desigualdades do acesso às tecnologias digitais em redes. O mesmo sentimento que envolve(nos) 'docentesdiscentes' nesse instante é o que envolvia Nathercinha na espera das cartas de seu tio, Paulo Freire, quando estava no Chile e ela no Brasil

Naquela época, as cartas demoravam muito a chegar. Lembro-me de aguardar, ansiosa, as respostas. Eu gostava especialmente de ler o que Paulo escrevia 
sobre as estações do ano no Chile: as cordilheiras nevadas, os flocos de neve no corpo, as flores, as roseiras risonhas, os vários tons das folhas no outono. [...] essa correspondência é um tesouro. Um tesouro para mim, que guardo desde menina (LACERDA, 2016, p. 41)

Diante desse inesperado mundial não paralisamos; ao contrário estamos mobilizados e, cada vez mais implicados, na busca de novos caminhos, crendo que ao formarmos o outro, somos por ele formados, numa relação de alter-ação, superando a alteridade (ideia do outro) para compreendê-lo em suas ações (Macedo, Barbosa, Borba, 2012) em um encontro real com suas oposições e sua complexidade. Faz-se necessário olhar para o lado e ver que, mesmo que fisicamente a presença desse outro não se faça, ressignifiquemos os 'espaçostempos' de aprendizagem, fazendo com que suas palavras e imagens sigam produzindo as flores e frutos de cada dia.

\section{CONSIDERAÇÕES FINAIS}

Caminhante, são tuas pegadas o caminho e nada mais; caminhante, não há caminho, se faz caminho ao andar. (Antonio Machado ${ }^{26}$ - "Cantares")

Finalizamos nosso artigo com esta passagem do poeta espanhol, que mesmo de nacionalidade distinta da de Paulo Freire, nos traz reflexões que coincidem com o que aqui discutimos e com o que acreditamos estar em consonância com as ideias freireanas. Optar por uma 'escritaleitura' que conversa com Freire, é acreditar acima de tudo que "Paulo Freire é um pensador comprometido com a vida: não pensa ideias, pensa a existência", como afirma o professor Ernani Maria Fiori, ao iniciar o prefácio do livro "Pedagogia do Oprimido" (19702014, p. 11). Dialogar com Paulo Freire demanda posicionamento daquele que escreve, reivindica responsabilidade sobre suas ações e produções no mundo, exige engajamento e escolha. Nesse caminho não há espaço para a neutralidade, posto que o ato pedagógico necessariamente é um ato político. Não há lugar para a homogeneização que desumaniza, resultado de uma produção social colonizadora que se propõe a apagar as diferenças. Se faz necessária uma prática educativa que desenvolva as sensibilidades, a tolerância, que encontre na diversidade as dimensões do único, das singularidades.

\footnotetext{
${ }^{26}$ Antonio Machado foi um poeta espanhol autor de diversos textos. Este é o trecho de um de seus poemas que pode ser encontrado na íntegra em: https://www.escritas.org/pt/t/10543/cantares. Acesso em 30 de mai. 2021.
} 
É preciso identificar-se com seus ideais, encontrar-se em suas palavras de educador sincero e comprometido; sentir-se incomodado com a injustiça e desigualdade social e almejar transformar as relações de dominação; conscientizar-se coletivamente; acreditar realmente que o diálogo é a ponte que movimenta os diferentes saberes existentes, sendo a chama da prática da liberdade; compreender que todo ser é histórico e sua história é única e, acima de tudo, acreditar que o amor é a energia necessária a todos nós, e deve estar presente nas múltiplas relações humanas.

Pudemos observar nos diferentes âmbitos educacionais, tanto nas escolas quanto nas universidades, o despontar de singularidades pouco percebidas. O que mais é levado em conta nesse contexto pandêmico é a falta que faz essa relação, as vivências, os acontecimentos, os abraços, as palavras ditas e não ditas. A pandemia tem trazido consigo esse sentimento de incertezas, desse 'inédito viável'. O 'aprenderensinar' na educação online precisa caminhar junto as contribuições de Paulo Freire sobre uma prática de construção de saberes que privilegie o diálogo, a colaboratividade e a interatividade. Essa troca entre professores e educandos se faz extremamente importante, e as telas dos celulares e computadores podem ser úteis para impulsionar novas práticas pedagógicas.

É neste sentido que entrelaçamos nossas práticas e pesquisas, na intenção de, no comprometimento com a vida, percebermos e valorizarmos os acontecimentos que dela emergem, em relação com o outro e com o eu; nas transformações e deformações pelas quais passam nossos processos subjetivos em constante diálogo com o coletivo. Assim, como nos referimos ao iniciar este artigo, buscamos por experiências e contribuições que valorizem as práticas educativas em seu sentido mais humano, libertador, relacional e holístico, acreditando que são essas as características - entre outras que surgirão nos caminhos da vida - que compõem a sinfonia de uma educação que procura desconstruir dicotomias distanciadoras, insensíveis e normatizadoras.

\section{REFERÊNCIAS}

ANDRADE, Nívea; CALDAS, Alessandra N.; ALVES, N. Os movimentos necessários às pesquisas com os cotidianos - 'após muitas conversas acerca deles'. In: Oliveira Inês; Peixoto, Leonardo; Süssekind, Maria. Luiza. (Orgs). Estudos do cotidiano, currículo e formação docente: questões metodológicas, políticas e epistemológicas. Curitiba: CRV, 2019, p. 19-45.

BARBIER, René. A pesquisa-ação. Tradução de Lucie Dibio. Brasília: Liber Libro, 2007. 
ELIADE, Mircea. Yoga: imortalidade e liberdade. São Paulo: Palas Athena, 1996.

FLAK, Micheline.; COULON, Jacques. Yoga na educação: interação corpo e mente na sala de aula. Florianópolis: Comunidade do Saber, 2007.

FOUCAULT, Michel. Vigiar e punir: nascimento da prisão. 42. ed. Petrópolis: Vozes, 2014.

FREIRE, Paulo. Pedagogia da esperança: um reencontro com a pedagogia do oprimido. $17^{\mathrm{a}}$ Ed. Rio de Janeiro: Paz e Terra, 2011

FREIRE, Paulo. Professora, sim; tia, não [recurso eletrônico] cartas a quem ousa ensinar / Paulo Freire. - 24. ed. rev. e atual. - Rio de Janeiro: Paz e Terra, 2015.

FREIRE, Paulo. Pedagogia da autonomia: saberes necessários à prática educativa. $66^{\mathrm{a}}$ ed. São Paulo: Paz e Terra, 2020.

FREIRE, Paulo. Pedagogia do oprimido. $74^{\mathrm{a}}$ ed. Rio de Janeiro/São Paulo: Paz e Terra, 2020a.

GALLEFI, Dante. Prefácio. In: Macedo, Roberto S. A pesquisa e o acontecimento: compreender situações, experiências e saberes acontecimentais. Salvador: Edufba, 2016. Disponível em: https://repositorio.ufba.br/ri/bitstream/ri/32184/1/A\%20pesquisa\%20e\%20o\%20aconteciment o\%20RI.pdf._Acesso em: 04 fev. 2021.

JESUS, Carolina M. Quarto de despejo: diário de uma favelada. São Paulo: Ática, 2001, $8^{\text {a }}$ ed.

JOSSO, Marie Christine. O corpo biográfico: corpo falado e corpo que fala. Educação \& Realidade, 2012, v. 37, n. 1, p. 19-31.

KINCHELOE, Joe L.; BERRY, Kathleen SS. Pesquisa em educação: conceituando a bricolagem. Porto Alegre: Artmed, 2007.

KRENAK, Ailton. Ideias para adiar o fim do mundo. Companhia das Letras, 2019.

LACERDA, Nathercia. A casa e o mundo lá fora: cartas de Paulo Freire para Nathercinha. Rio de Janeiro: Zit, 2016.

LEMOS, André. Cibercultura: tecnologia e vida social na cultura contemporânea. 8. ed. Porto Alegre: Sulina, 2020.

LÉVY. Pierre. Cibercultura. Trad. Carlos Irineu da Costa. Rio de Janeiro: Ed. 34, 1999. 
MACEDO, Roberto Sidnei. A pesquisa como heurística, ato de currículo e formação universitária: experiências transingulares com o método em ciências da educação. Campinas: SP: Pontes Editores, 2020.

MACEDO, Roberto Sidnei; BARBOSA, Joaquim Gonçalves; BORBA, Sérgio. Jacques Ardoino \& a educação. Belo Horizonte: Autêntica, 2012.

MORIN, Edgar. É hora de mudarmos de via: as lições do coronavírus. São Paulo: Bertrand, 2020 .

POMBO, Surya. DIAS, Amália. Não-brancos (as) e periféricos (as): histórias da docência no Brasil. Revista Brasileira de Educação, 2020, v. 25.

PATANJALI. Os Yoga sutras de Patanjali [livro eletrônico]. Carlos Eduardo G. Barbosa [tradução do sânscrito]. São Paulo: Mantra, 2019.

ORGANIZAÇÃO PAN-AMERICANA DA SAÚDE. Entenda a infodemia e a desinformação na luta contra a COVID-19. OPS/IMS/EIH/COVID-19/20-0006. 2020. Disponível em: https://iris.paho.org/handle/10665.2/52054. Acesso em: 02/05/2021.

ORGANIZAÇÃO DAS NAÇÕES UNIDAS. Transformando nosso mundo: A Agenda 2030 para o desenvolvimento sustentável. ONU. 2015. Disponível em: https://bit.ly/2KV0uZD. Acesso em: 28 novembro 2020.

RIBEIRO, Mayra; SANTOS, Edméa. Pesquisa-formação multirreferencial e com os cotidianos na cibercultura: tecendo a metodologia com um rigor outro. Revista de Educação Pública, 2016, v. 25, n. 59/1, p. 295-310.

SANTAELLA, Lúcia. Comunicação ubíqua: repercussões na cultura e na educação. São Paulo: Paulus, 2013.

SANTOS, Boaventura de S. A cruel pedagogia do vírus. São Paulo: Boitempo, 2020.

SANTOS, Edméa. Pesquisa-formação na cibercultura. Teresina: EDUFPI, 2019. [E-book].

Este é um artigo de acesso aberto distribuído sob os termos da Licença Creative Commons Atribuição Não Comercial-Compartilha Igual (CC BY-NC- 4.0), que permite uso, distribuição e reprodução para fins não comerciais, com a citação dos autores e da fonte original e sob a mesma licença. 